\title{
Resíduos Sólidos Como Ferramenta de Educação Ambiental para Grupos do Projovem do Centro de Referência de Assistência Social um Lugar ao Sol
}

\author{
Solid Waste as a Tool of Environmental Education for Groups of Reference Service \\ Center Projovem Social a Place In The Sun
}

\author{
Fátima Rosane Pieniz Sant'anna ${ }^{1}$; Jorge Orlando Noguera ${ }^{2}$
}

${ }^{1}$ Especialista em Educação Ambiental, aluna do Polo Presencial de Panambi,RS, Brasil.

${ }^{2}$ Orientador, Coautor, Dr. UFSM, RS, Brasil.

\section{Resumo}

Esta pesquisa foi desenvolvida junto ao Centro de Referência de Assistência Social - CRAS Um Lugar ao Sol, pertencente à Secretaria de Desenvolvimento Social do Município de Cruz Alta, Rio Grande do Sul. O CRAS Um Lugar ao Sol fica localizado na zona leste do Município de Cruz Alta, no Bairro Jardim Primavera II. O público alvo deste estudo foram os jovens pertencentes ao Coletivo de ProJovem Adolescente do referido CRAS, com idades entre 15 e 17 anos, estudantes da Escola Maria Bandarra Westphalen, do mesmo bairro. Foi avaliada a atitude dos jovens para com o Meio Ambiente e incentivado a mudanças de hábitos e práticas que promovam o consumo consciente e a destinação adequada aos resíduos domésticos. Para tanto, os jovens se organizaram em grupos e realizaram o experimento de coleta dos resíduos orgânicos de suas próprias residências durante quatro semanas, observando o peso destes resíduos e fazendo o apontamento de todo o processo de decomposição dos mesmos para a elaboração de compostagem. Os apontamentos feitos pelos grupos ao final do trabalho foi debatido por todos com resultados positivos em relação ao interesse na utilização destes resíduos domésticos como compostagem. Dentro do contexto do ambiente socioassistencial às diferentes formas com que os usuários das políticas públicas vivenciam em seus trabalhos na família, comunidade, em suas lutas diárias pela moradia, por saúde, por assistência social pública, cidadania e questões ambientais a Educação Ambiental, pode, ainda, servir como mediadora entre o social e o ecológico, entre os cidadãos e a sociedade, pois a ampliação e a consolidação da cidadania são princípios que garantem os direitos civis, sociais ou políticos. A saúde e o bem estar da população dependem da qualidade do Meio Ambiente onde ela se encontra inserida e pode servir de instrumento na construção de uma sociedade mais justa e sustentável.

Palavras-Chave: ProJovem - Compostagem - Sustentabilidade

\section{Abstract}

This monograph was developed by the Social Assistance Reference Center -CRAS A Place in the Sun, owned by the Department of Social Development of Alta Cruz, Rio Grande do Sul CRAS A Place in the Sun is located on the east side of the City, Spring in the Garden District II. The target audience of this study were young people belonging to the Group of ProJovem said Adolescent CRAS, aged 15 to 17 years, students of the School Maria Bandarra Westphalen, the same neighborhood. The attitude of young people was evaluated for the environment and insentivado to change habits and practices that promote consumer awareness and proper disposal of household wastes. For both young people organized themselves into groups and performed the experiment collection of organic waste from its own residênicas for four weeks, observing the weight of the waste and making the appointment of the whole process of decomposition thereof for the preparation of compost. The notes made by the groups at the end of the work was discussed by all with positive results in relation to the interest in the use of household waste as compost. Within the context of social assistance environment to the different ways that users of public policy experience in their work in the family, community, in their daily struggles for housing, for health, for public welfare, citizenship and environmental issues Environmental Education may also serve as a mediator between the social and the ecological, between citizens and society, as the expansion and consolidation of citizenship are principles that guarantee civil, social or political. The health and well being of the population depend on the quality of the environment where it is inserted, and can be instrumental in building a more just and sustainable society. 


\section{Introdução}

Não se pode falar em meio ambiente sem abordar sobre os desequilíbrios causados a ele durante a longa trajetória da humanidade. Desde o efeito estufa, a falta de tratamento dos resíduos sólidos e orgânicos, o aquecimento global, enfim, tudo está relacionado com o mau uso do meio ambiente pelo homem. As relações socioambientais podem ser promovidas no sentido de que o reaproveitamento dos resíduos domésticos, a redução na geração dos mesmos possam ser formas de equilibrar o ambiente em que vivemos. Ao contrário do que ocorre em grandes centros urbanos, ou em países de primeiro mundo, onde o consumismo é a base econômica da sociedade, pudesse começar o trabalho de Educação Ambiental junto às classes menos favorecidas, que muitas vezes sobrevivem justamente das sobras ou dos materiais recicláveis descartados pelo resto da sociedade e que só tendem a aumentarem o volume já intolerável dos lixões ou aterros sanitários.

Esta pesquisa visa buscar alternativas para se implantar e trabalhar a Educação Ambiental dentro do ambiente do Centro de Referência de Assistência Social, junto aos Coletivos de ProJovem Adolescente, onde jovens atendidos pela rede de Assistência Social do Município de Cruz Alta, em sua maioria filhos de catadores de materiais recicláveis possam aprender maneiras de fazer o aproveitamento dos resíduos domésticos gerados em suas próprias residências para fazerem compostagem, visando fortalecer a sustentabilidade destas famílias e das comunidades onde vivem, uma vez que poderão propagadores da ideia de aproveitamento dos resíduos domésticos para transformarem em compostagem. A realidade do cotidiano destes jovens poderá se transformar em exemplo na comunidade em que vivem, uma vez que poderão fazer repercutir as práticas ambientais aprendidas dentro do coletivo do CRAS. Essas atitudes simples podem se tornar iniciativas que, em longo prazo, podem contribuir para a diminuição dos impactos ambientais da sociedade.

O problema da pesquisa consistiu em inserir a educação ambiental no CRAS Centro de Referência de Assistência Social para complementar a formação dos jovens que frequentam os grupos de ProJovem.

O objetivo geral consistiu em usar os resíduos sólidos como ferramenta para desenvolver um projeto e ações de Educação Ambiental que eduquem para a mudança de hábitos os jovens do $9^{\circ}$ ano da Escola Maria Bandarra de Cruz Alta.

Um dos objetivos da Política Nacional de Assistência Social é: "prevenir situações de risco por meio de desenvolvimento de potencialidades e aquisições, buscando o fortalecimento de vínculos familiares e comunitários" PNA/2005). Seus serviços, programas e projetos destinam-se a população em situação de vulnerabilidade social decorrente de pobreza e possíveis discriminações etárias, de gênero, étnicas, entre outras, neste contexto, inserir a educação ambiental é de suma importância para enriquecer o aprendizado destes jovens. Para Sorrentino (1988), entre os grandes desafios dos educadores ambientais estão o resgate e o desenvolvimento de comportamentos e valores como o respeito mútuo, confiança, compromisso, responsabilidade, solidariedade e iniciativa, por outro lado é necessário promover uma visão global e crítica das questões ambientais de forma interdisciplinar no sentido de resgatar e construir saberes.

\section{Revisão Bibliográfica}

\subsection{O Programa Projovem Adolescente e a Educação Socio Ambiental}

A educação ambiental pode ser inserida em diversos contextos da sociedade, sob a perspectiva educativa, podendo ser abordada em todas as disciplinas. Quando se pensa sobre as relações do homem e o meio ambiente em relação ao social, percebemos que os propostas da educação ambiental devem ser principalmente a conscientização, 0 conhecimento, a competência, o comportamento e a capacidade de promover uma 
avaliação do meio ambiente como um todo. No Congresso de Belgrado, a educação ambiental foi denominada como:

\begin{abstract}
Um processo que visa: formar uma população mundial consciente e preocupada com o ambiente e com os problemas que lhe dizem respeito, uma população que tenha os conhecimentos, as competências, o estado de espírito, as motivações e o sentido de participação espírito, as motivações e o sentido de participação e engajamento que the permita trabalhar individualmente e coletivamente para resolver os problemas atuais e impedir que se repitam (CONGRESSO DE BELGRADO, 1975).
\end{abstract}

A política nacional de assitência social deu um importante passo em 2006, segundo documentos do Minstério do Desenvolvimento Social e Combate a Fome, uma mudança significativa foi conseguida em assembléia onde o Conselho Nacional de Assistência Social - CNAS - e o Conselho Nacional de Assistencia Social - CONANDA, fizeram a aprovação do plano nacional de convivência familiar e comunitária, em 13 de dezembro de 2006. Com esse plano, elaborado no intuíto de observar as iniciativas de apoio sociofamiliar e comunitário, mapear e apontar dados sobre adolescentes e crianças que estão sob os cuidados de terceiros sem determinação judiciária ou então que estejam em situação de rua, ou ainda em programas de acolhimento institucional para que sejam assistidos pelas Centros de Referência Especializada - CREAS ou pelos Centros de Referência de Assistência Social - CRAS, em projetos que visem a inclusão produtiva. Foi acordado inclusive das capacitações voltadas aos gestores e estimulando projetos com atividades de mobilização como parte das estratégias que venham a contribuir para que crianças não necessitem serem colocadas nos abrigos, ou que necessitem trabalhar em situação de rua, ou ainda venham sofrer abuso e exploração sexual. Esta assembléia garantiu ainda a matricidade familiar, bm como o convívio comunitário.

\footnotetext{
Proteger a criança e o adolescente propiciar-lhes as condições para o seu pleno desenvolvimento, no seio de uma família e de uma comunidade, ou prestar-lhes cuidados alternativos temporários, quando afastados do convívio com a família de origem, são antes de tudo e na sua essência, para além de meros atos de generosidade, beneficência, caridade ou piedade, o cumprimento de deveres para com acriança e o adolescente e o exercício da responsabilidade da família, da sociedade e do Estado (BRASIL, 2006b, p. 25).
}

Esse programa de fortalecimento da convivência familiar e comunitária com a intenção de promover um novo olhar em torno do acompanhamento social, visando a promoção da soberania dentro das famílias. Após este novo redirecionamento da política de assistência social, novos programas sociais foram agregados enfatizando a matricial idade familiar, sendo fundamentada em várias unidades:

Unidade pública da política de assistência social, de base municipal, integrante do SUAS, localizado em áreas com maiores índices de vulnerabilidade e risco social, destinado à prestação de serviços e programas sócio assistenciais de proteção social básica às famílias e indivíduos, e à articulação destes serviços no seu território de abrangência, e uma atuação Inter setorial na perspectiva de potencializar a proteção social (BRASIL, 2010a).

Unidade pública e estatal onde se ofertam serviços especializados e continuados a famílias e indivíduos nas diversas situações de violação de direitos. Como unidade de referência deve promovera integração de esforços, recursos e meios para enfrentar a dispersão dos serviços e potencializar ações para os (as) usuários (as) (BRASIL, 2010b). 
Assim, para complementar, foi incluído o Programa Bolsa Família, programa de transferência de renda direta, mas embasado em condicionalidades a serem cumprida em relação à saúde e à escolaridade.

O Programa Bolsa Família foi regulamentado pela Lei $n^{\circ} 10.836$, de 09 de janeiro de 2004, é integrante das estratégias que visam assegurar o direito à alimentação adequada, promovendo assim a segurança nutricional e alimentar, visando principalmente a erradicação da extrema pobreza e a conquista da cidadania pela população que vive a margem da sociedade. Para tanto o Programa Bolsa Família beneficia famílias em situação de pobreza com renda per capita atual de $\mathrm{R} \$ 77,00$ a $\mathrm{R} \$ 154,00$ com as variáveis de $\mathrm{R} \$$ 35,00 por crianças, beneficiando até 5 crianças por família, e R $\$ 42,00$ variável jovem, beneficiando até 2 jovens por família. As famílias em extrema pobreza, com renda até $\mathrm{R} \$$ 77,00 , recebem além das variáveis, um valor básico de $\mathrm{R} \$ 77,00$.

O Instituto Brasileiro de Geografia e Estatística - IBGE em 2008, após realizar a Pesquisa Nacional por Amostra de Domicílio - PNAD, visando medir o plano de atendimento às famílias, divulgou dados que apontam a diminuição em torno de seis milhões de pessoas que viviam em situação de extrema pobreza no país.

$\mathrm{O}$ fortalecimento de vínculos familiares se faz necessário desde o nascimento, no sentido de se ter um pertencimento a uma família, a um local, pois as crianças não formam uma comunidade isolada, mas sim parte de um grupo e desde suas brincadeiras já expressam seu pertencimento.

Segundo Kramer (2008, p.p. 171-172) "Como sujeitos sociais, as crianças nascem no interior de uma classe, de uma etnia, de um grupo social. Os Costumes valores hábitos interferem em suas ações e nos significados (...).

A sociedade necessita perceber a criança como ser único, fazendo parte da mesma, como um ser único, pertencendo a uma comunidade que tem seu próprio meio de agir e pensar, neste contexto de relações diversas faz com que gradativamente esta criança seja atendida até chegar a sua adolescência.

A política voltada para o adolescente e o meio social e familiar em que o mesmo está inserido, sua constituição como pessoa, enfocando a importância da família na formação de sua personalidade. A adolescência tem seu começo por volta dos 12 anos e é marcada por diversas transformações corporais e psicológicas, principalmente pelo amadurecimento sexual, bem como as transformações de conotação psicológica e dos sentimentos afetivos.

A adolescência é uma parte da vida, as transformações físicas psíquicas, sociais e emocionais marcam tanto quanto os conflitos pessoais, internos ou familiares. Deixamos de sermos crianças para atravessar um caminho longo até atingirmos a fase adulta, mas é uma fase importantíssima para o desenvolvimento da personalidade.

A intolerância faz parte constante da vida dos adolescentes, principalmente com relação ao controle dos pais, ou ao fato de terem de seguir regras de boa conduta e o meio social e cultural passa ser percebido com grande importância pelos mesmos, necessitam ainda se sentirem identificados com seu grupo de amigos. Nesta fase podemos perceber visivelmente como o meio social pode condicionar a vivência das pessoas, podendo interferir em sua personalidade em muitos sentidos.

$\mathrm{Na}$ fase da adolescência Percebe-se as grandes diferenças existentes entre as juventudes e suas classes sociais, segundo Bourdieu (1980,p.p. 113-114): "Uma é constituída pelos filhos de famílias operárias desprovidas de recursos materiais, na qual o trabalho é a busca principal para se pertencer ao mundo; não tem estudo, segurança e outros elementos identifica tórios, (lazer, roupas, etc.)".

É fácil então perceber que as grandes diferenças de classes sociais, uma vez que os jovens de classe média conseguem se expressar, elaborar questionamentos em relação a padrões morais, enquanto que em contraste a isso, nas classes operárias, onde a necessidade de se trabalhar e encarar a vida dura desde cedo, faz com que os jovens pulem a fase da adolescência precocemente e vivam a realidade do adulto.

A realidade da classe de jovens economicamente inferiores é a de muitas vezes terem de abandonar a escola, para ajudarem no sustento de suas famílias, entrando pelo 
caminho de um trabalho informal, enfrentando muitas vezes a exploração e alienação neste seu intento, mediante a uma sociedade capitalista e dominadora, que ainda hoje coloca multidões à margem da sociedade. Com toda essa problemática, ainda é comum perceber que grande parte da juventude segue os passos de seus pais, de se acomodarem e não buscarem o que seria garantido por direito. Segundo Cardoso (2005, p.27):"A juventude, com sua adversidade, anseios, posturas, preocupações, tendências e comportamentos - por vezes contraditórios, move-se em busca da felicidade e, no fundamental, por generosos valores de solidariedade e de partilha".

A família é o primeiro berço para o processo de construção das relações sociais, sua importância está ressaltada no Estatuto da criança e do adolescente, com enfoque para a perspectiva de deveres da família, em vista de resultados conseguidos através de vários projetos sociais voltados para a criança e o adolescente de todo o país.

Deixando de lado os tempos em que se tratavam crianças e adolescentes baseados em situação de vulnerabilidade apenas com filantropia, que largamente é vista como um atraso no desenvolvimento educacional, pois somente uma minoria tinha acesso a qualificação adequada, muitas vezes em decorrência da baixa escolaridade, ou do analfabetismo funcional, ou seja, proveniente de indivíduos que mesmo sabendo ler, não é capaz de fazer a interpretação de textos, ou ainda de conseguir aplicar o que the foi ensinado, o que resulta em desestímulo dos mesmos. Segundo Freire (2005):

\footnotetext{
A educação libertadora é incompatível com uma pedagogia que, de maneira consciente ou mistificada, tem sido prática a prática dominação. A prática da liberdade só encontrará adequada expressão numa pedagogia em que o oprimido tenha condições de, reflexivamente, descobrir-se e conquistar-se como sujeito de sua própria destinação histórica ( FREIRE, 2005, p. 7).
}

O Sistema Único de Assistencia Social - SUAS engloba todas as políticas de Assistencia Social do País, sendo norteado pela NOB SUAS, dentro dos projetos da rede SUAS está o Pro Jovem Adolescente. O Programa ProJovem Adolescente - Serviço de Convivência e Fortalecimento de Vínculos para Adolescentes e Jovens, é uma reestruturação do programa Agente Jovem de Desenvolvimento Social e Humano, e tem como objetivo assegurar a segurança social aos jovens bem como suas famílias. Entre suas pretenções está atender e articular ações de proteção básica e especial aos jovens. (BRASIL, 2009). O programa atende a uma faixa de idade de jovens de 15 a 17 anos, que se enquadrem nas seguintes categorias:

\footnotetext{
a) adolescentes e jovens pertencentes às famílias beneficiárias de programas de transferência de renda; b) adolescentes e jovens egressos de medida sócio-educativa de internação ou em cumprimento de outras medidas sócio-educativas em meio aberto, conforme disposto no Estatuto da Criança e do Adolescente; c) adolescentes e jovens do Programa de ação do Trabalho Infantil (PETI) ou adolescentes e jovens egressos ou vinculados a rogramas de combate à violência e ao abuso e a exploração sexual;d) e jovensde famílias com perfil de renda de programas de transferência de renda; e) jovens com deficiência, em beneficiários do Benefício de Prestação Continuada (BPC); f) jovens fora da escola (PROJOVEM ADOLESCENTE - TRAÇADO METODOLÓGICO, 2009)
}

O traçado metodológico do programa ProJovem Adolescente tem por objetivo promover o protagonismo dos jovens, despertando seu reconhecimento destes, enquanto sujeitos de direitos sociais e cidadania, muito diferente da sociedade opressora, que impões contextos que enchem de conteúdos vazios e de forma mecanizada e utilitarista capaz de expropriar a vida destes jovens. Os temas propostos pelo ProJovem do Ministério do Desenvolvimento Social e Combate à Fome, são bem embasados e têm conteúdos 
abrangentes que norteiam e direcionam os jovens para uma futura emancipação. Em Demo (1994), encontramos o seguinte:

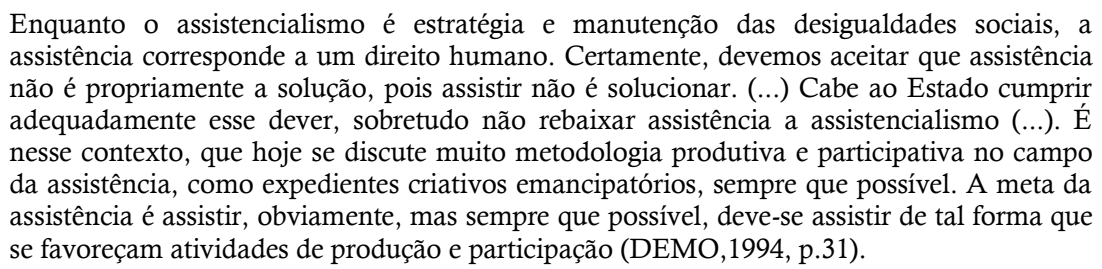

Para FREIRE (1996): "o respeito à autonomia e à dignidade de cada um é imperativo ético e não um favor que podemos ou não conceder uns aos outros".

\section{Metodologia}

A metodologia para o desenvolvimento desta pesquisa classifica-se como qualitativa, investigativa e experimental. Teve como base o Coletivo de ProJovem Adolescente, dentro do Centro de Referência de Assistência Social - CRAS Um Lugar ao Sol, no Bairro Jardim Primavera II, na Cidade de Cruz Alta - RS. Participaram deste trabalho 12 (doze) jovens, com idades entre 15 à 17 anos, estudantes do $9^{\circ}$ ano da Escola Estadual Maria Bandarra Westphalen que fica localizada no mesmo Bairro.

Inicialmente foi aplicado um questionário, após palestra, trabalhos de grupos, coleta de resíduos sólidos domiciliares, observações e análises das atividades aplicadas utilizando-se os resíduos coletados. E por útimo Relatório avaliando as atividades desenvolvidas.

\section{Resultados e Discussão}

Com base na metodologia descrita, apresenta-se a seguir os resultados obtidos com a pesquisa:

\section{Resultados da Palestra "Resíduos Sólidos e Sustentabilidade", Diálogo e Aplicação Ddo Questionário "Sustentabilidade"}

No primeiro contato efetuado em 15 de julho de 2014, se iniciaram os trabalhos com a palestra sobre "Resíduos Sólidos e Sustentabilidade", onde ao término desta, houve uma conversa informal, para a observação do grau de interesse dos jovens.

Inicialmente observou-se que os participantes que estavam um pouco retraídos, mas logo houve a integração de todos para a discussão. Percebeu-se que a preocupação com o Meio Ambiente se faz presente entre os jovens, mas que culturalmente eles não tem o hábito e nem sabem por onde começar na preservação do mesmo.

Em seguida foi aplicado o questionário também elaborado por esta autora "Reciclagem e Meio Ambiente", com 10 (dez) questões fechadas no qual foram observados onde segue abaixo os respostas mais relevantes neste estudo:

Dentre as perguntas respondidas pelos jovens, está a pergunta: "Em sua residência vocês tem o hábito de separar o lixo reciclável (pet, papelão, plástico, vidro, metais, etc.) do lixo orgânico (restos de comida, cascas de legumes e frutas, etc)?"De acordo com as respostas, as famílias em sua maioria $67 \%$ já faz a separação dos resíduos residenciais, e fica mais evidente com as respostas da segunda pergunta: "Você acha a reciclagem importante para a preservação do meio ambiente?", sendo que em torno de $83 \%$ das respostas foram afirmativas, demonstrando que a preocupação com o meio ambiente faz 
parte destas famílias.

Quanto a destinação do lixo produzido nas residências (pergunta 3), somente $33 \%$ dos jovens dizem disponibilizar estes resíduos para serem recolhidos por catadores. A maioria, cerca de $92 \%$ também diz não saber nada sobre a destinação final dos resíduos orgânicos do município (pergunta 4). Outro fato observado é que poucos têm hábito de jogarem os lixos nas lixeiras em locais públicos ou na escola, pois somente $24 \%$ diz que costuma colocá-los na lixeira (pergunta 5).

\begin{tabular}{|c|c|c|c|}
\hline & PERGUNTA & SIM & NÃO \\
\hline 1 & $\begin{array}{l}\text { Em sua residência vocês tem o hábito de separar o } \\
\text { lixo reciclável (pet, papelão, plástico, vidro, } \\
\text { metais, etc.) do lixo orgânico (restos de comida, } \\
\text { cascas de legumes e frutas, etc)? }\end{array}$ & 8 & 4 \\
\hline 2 & $\begin{array}{l}\text { Você acha a reciclagem importante para a } \\
\text { preservação do meio ambiente? }\end{array}$ & 10 & 2 \\
\hline \multirow[t]{3}{*}{3} & \multicolumn{3}{|c|}{ O que sua família faz com o lixo produzido ne sua residência? } \\
\hline & a) separa para ser recolhido pelos catadores & 4 & 8 \\
\hline & $\begin{array}{l}\text { b) coloca na lixeira para ser recolhido pelo } \\
\text { caminhão }\end{array}$ & 8 & 4 \\
\hline 4 & $\begin{array}{l}\text { Você sabe o que acontece com o lixo recolhido } \\
\text { em nossa cidade? }\end{array}$ & 1 & 11 \\
\hline 5 & Você joga lixo no chão na escola ou na rua? & 2 & 10 \\
\hline 6 & $\begin{array}{l}\text { Você já participou de algum projeto de materiais } \\
\text { recicláveis? }\end{array}$ & 3 & 9 \\
\hline 7 & $\begin{array}{l}\text { Você já utilizou algum material que iria para o } \\
\text { lixo para fazer algo reutilizável? }\end{array}$ & 11 & 1 \\
\hline 8 & Você sabe o que é lixo orgânico? & 6 & 6 \\
\hline \multirow[t]{3}{*}{9} & \multicolumn{3}{|c|}{ Na sua residência o que vocês fazem com o lixo orgânico? } \\
\hline & a) como adubo & 1 & 11 \\
\hline & $\begin{array}{l}\text { b) colocam em sacos para ser recolhidos pelo } \\
\text { caminhão }\end{array}$ & 11 & 1 \\
\hline 10 & Você sabe o que é compostagem? & 3 & 9 \\
\hline
\end{tabular}

Quadro 1: Resultado do questionário

Fonte: Autora, pesquisa de Campo

Quanto ao interesse de participarem de projetos envolvendo o uso de materiais recicláveis, cerca de $75 \%$ dos jovens responderam que nunca participaram de nenhuma atividade deste tipo (pergunta 6). Já na pergunta 7: "Você já utilizou algum material que iría para o lixo para fazer algo reutilizável?", mostrou que em torno de $92 \%$ dos jovens já reutilizaram algum tipo de material que seria descartado, isso demonstra que mesmo sem terem noção sobre reciclagem, muitas vezes a mesma ocorre no cotidiano deles.

Já a pergunta sobre o conhecimento do que é lixo orgânico (pergunta 8), em torno de $50 \%$ dos jovens responderam que não sabem distinguir o que é este tipo de lixo, e a falta de interesse nos resíduos orgânicos fica mais evidente na pergunta 9 , onde $100 \%$ dos jovens responderam que este tipo de lixo é colocado para ser recolhido pelo caminhão de coleta. Já a pergunta 10: "Você sabe o que é compostagem?", cerca de $90 \%$ dos jovens responderam que não sabem do que se trata.

\section{Resultados da Palestra "Coleta Seletiva Domiciliar"}


No segundo encontro em 22 de julho, foi aos jovens a palestra de autoria do Professor Jorge Orlando Cuellar Noguera "Coleta Seletiva Domiciliar". Após a apresentação, todos debateram o tema apresentado, sobre o grau de facilidade quanto a separação dos resíduos domésticos e alguns jovens colocaram suas opiniões sobre o assunto. A figura $\mathrm{n}^{\mathrm{o}} 1$ mostra um aspecto deste encontro.

\section{Resultados da Formação de Grupos de Trabalho}

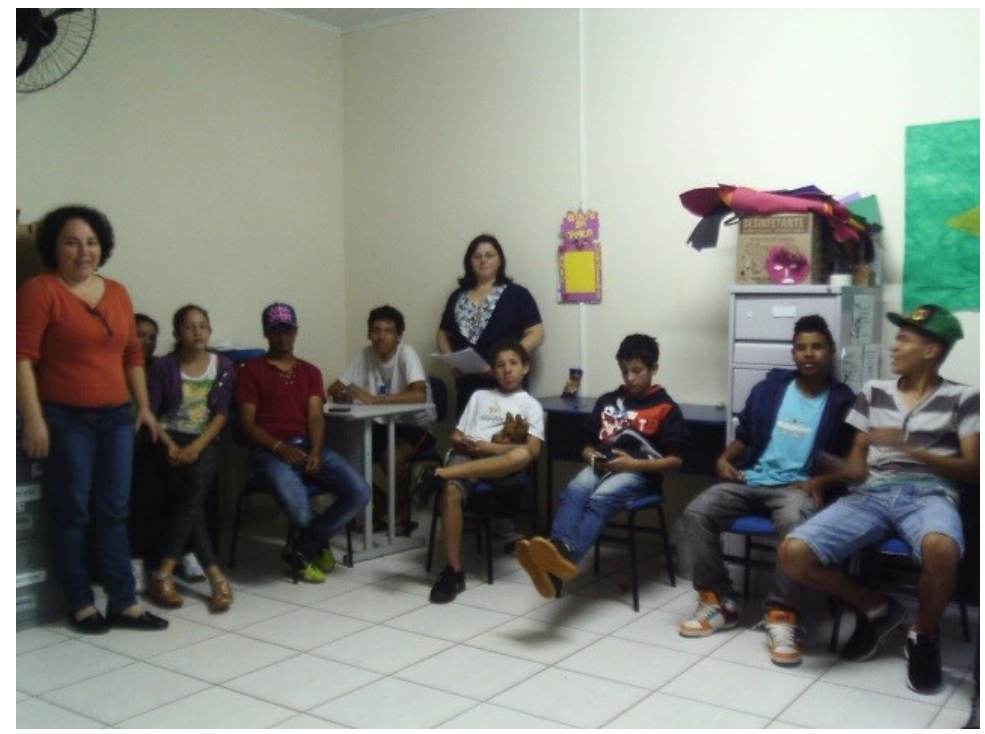

Figura 1: Encontro de trabalho

Fonte: Autora

Após as discussões, com os 12 (doze) jovens presentes e segundo os criterios da metodologia se formaram 3 (três) grupos de 4 (quatro) pessoas para desenvolver suas atividades.

No próximo encontro todos trouxeram ao CRAS os resíduos orgânicos coletados durante a semana em suas residências, que foram pesados individualmente, sendo que as anotações foram feitas (por grupo) e posteriormente estes resíduos foram depositado em um balde (cada grupo com seu balde).

\section{Resultados Palestra "Compostagem Doméstica"}

Houve uma discussão sobre o assunto após a palestra "Compostagem Doméstica", a qual pode-se observar que trouxe uma ampliação sobre a abrangência do experimento que os jovens iríam começar, sendo que ficou mais transparente também o grau de interesse sobre as atividades que estavam por vir.

Neste sentido e como resultado palestra sobre elaboração de compostagem, se iniciaram as ações com o início do experimento de compostagem no dia 29 de julho. Os jovens fizeram a pesagem dos resíduos orgânicos trazidos de suas residências, sendo que as anotações feitas podem ser vistas no Anexo $\mathrm{n}^{\circ} 2$. Estes residuos, após a pesagem, foram depositados em baldes (um balde por grupo) que ficaram tapados no pátio nos fundos do CRAS.

\section{Resultados da Pesagem dos Resíduos Orgânicos}


A tabela 1 mostra os resultados sobre o peso dos resíduos recolhidos durante as quatro semanas pelos grupos:

Tabela 1: Resultados em peso das observações nas quatro semanas.

\begin{tabular}{l|l|l|l|l|l}
\hline GRUPO & $1^{\text {a }}$ SEMANA & $2^{\text {a }}$ SEMANA & $3^{\text {a }}$ SEMANA & $4^{\text {a }}$ SEMANA & TOTAL \\
\hline 1 & 6,000 & 5,200 & 5,800 & 7,800 & 26,600 \\
\hline 2 & 7,300 & 7,630 & 8,050 & 5,800 & 28,780 \\
\hline 3 & 4,600 & 7,100 & 6,400 & 5,900 & 24,000 \\
\hline
\end{tabular}

Fonte: Pesquisa de campo realizada pela autora, 2014

Durante estas quatro semanas foram somente realizadas as pesagens dos resíduos recolhidos pelos grupos e o depósito em seus respectivos baldes, os quais se mantiveram tapados (com as tampas soltas em cima de cada um, sem que estivessem herméticamente fechados.

\section{Resultados da Observação dos Resíduos Orgânicos}

Após coleta de cada grupo com seus baldes, - os baldes com os resíduos ficaram tapados durante o experimento, para evitar somente a entrada da de água da chuva e uma maior a proliferação de insetos.
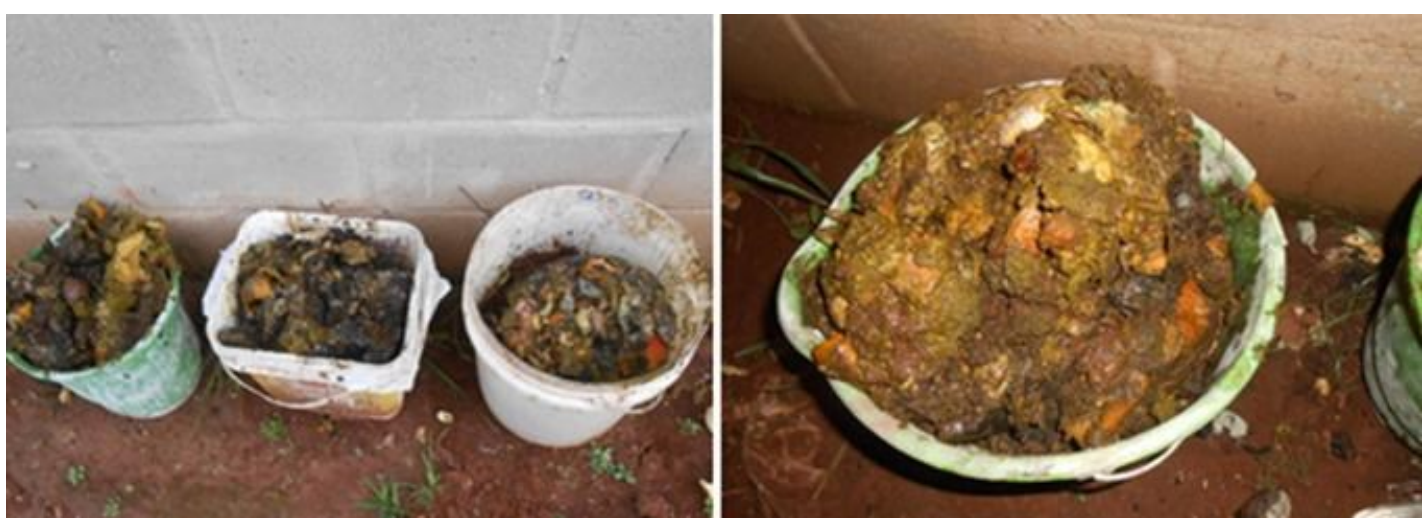

Figura 2: Resíduos orgânicos na $4^{\mathrm{a}}$ semana Figura 4: Resíduos orgânicos $8^{\mathrm{a}}$ semana Fonte: Pesquisa de Campo realizada pela Autora

$\mathrm{Na}$ quarta semana, após o início da coleta dos resíduos e do depósito dos mesmos nos baldes, os jovens elaboraram a seguinte atividade:

- Cada grupo despejou os resíduos de seu balde em outro balde. Os resultados como cheiro, temperatura, a presença de larvas, insetos, entre outros foram apontados por cada grupo. Este procedimento foi repetido por mais 4 (quatro) semanas.

$\mathrm{Na}$ oitava semana, os jovens se reuniram, cada qual com seu grupo, onde elaboraram um relatório final, o qual foi apresentado por um representante de cada grupo e resultados observados foram debatidos por todos.

\section{Relatório final sobre a Compostagem e Discussões}

Os principais apontamentos nos relatórios foram: 
- O mau cheiro quando do início do experimento, que foi reduzindo e chegando a ser bem fraco no final da oitava semana;

- A quantidade de mosca, mosquitos e larvas que ajudaram a promover a decomposição dos resíduos;

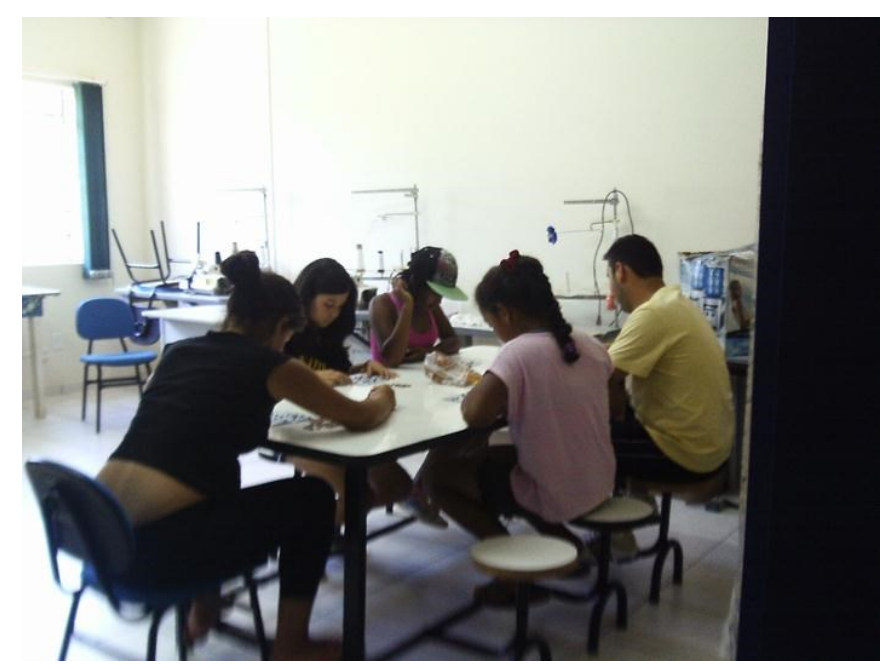

Figura 3: Jovens elaborando o relatorio final

Fonte: Autora

- A temperatura que nas primeiras semanas era mais alta, e depois foi baixando;O volume dos resíduos que foi diminuindo gradualmente; semanas;

- A cor dos resíduos que foi ficando cada vez mais escura com o passar das

- Todos acham que seria interessante se fosse colocado camadas de terra entre as camadas de resíduos, para que os resíduos ficassem mais secos e se incorporassem à torra mais facilmente.

\section{Conclusões}

Os objetivos desta pesquisa foram alcançados, pois o trabalho foi desenvolvido com êxito. O primeiro ponto positivo a ser apontado-que a Educação Ambiental pode e deve ser incluída dentro das atividades dos CRAS, bem como de todos os setores da Secretaria de Assistência Social, pois a temática do Meio Ambiente necessita ser difundida em todos os segmentos da sociedade.

A palestra "Resíduos Sólidos e Sustentabilidade" com a qual se iniciou os trabalhos junto aos jovens obteve o efeito desejado, que era poder mostrar a realidade sobre a problemática dos resíduos que são descartados pela humanidade todos os dias. Este resultado positivo também pode ser observado durante o diálogo sobre a temática apresentada, que serviu para que os membros do coletivo sanassem suas dúvidas sobre o assunto bem como colocassem um pouco da realidade vivenciada pelos mesmos. Quanto a aplicação do questionário "Sustentabilidade", se conclui que foi de grande importância, pois através das respostas se conseguiu mensurar o grau de entendimento e de interesse destes jovens em relação às causas ambientais.

A Palestra "Coleta Seletiva Domiciliar" conseguiu fazer com que os jovens percebessem detalhes sobre a temática abordada que eles nunca antes haviam dado importância, conforme o relato feito por eles mesmos após a exibição da mesma. A formação dos grupos de trabalho com divisão em três grupos de quatro pessoas, com a escolha dos membros pelos próprios jovens, de acordo com suas afinidades também foi 
importante para o bom resultado final, pois o entrosamento entre eles colaborou para que fizessem um bom trabalho.

Quanto ao experimento com a compostagem de resíduos domiciliares, não restam dúvidas que foram bem aceitas pelos jovens que participaram do experimento, bem como pelos vários atores que fazem parte do cotidiano do CRAS onde a atividade foi desenvolvida. Além dos benefícios ambientais produzidos pela compostagem, o experimento também proporcionou aos envolvidos a percepção da quantidade de resíduos que são jogados fora diariamente em nossas residências. A realização da pesagem dos resíduos orgânicos produzido nas residências também os deixou surpresos, pois além do peso ser elevado, eles também fizeram comentários sobre o volume dos resíduos sólidos gerados e demonstraram sua preocupação com o desperdício. Alguns jovens chegaram a expor o empenho em diminuir essa geração de resíduos.

Outro ponto importante foi o interesse dos jovens em dar continuidade com o experimento que fizeram, tanto no experimento com a compostagem começado no CRAS, que vai ainda levar algum tempo para estar pronto para ser usado, como na continuidade da coleta dos resíduos orgânicos de suas residências também para a elaboração da compostagem.

$\mathrm{O}$ experimento com a compostagem gerou ainda aos jovens o interesse de propagarem nas famílias, na escola em que frequentam, bem como na comunidade continuar difundindo a ideia, talvez com a ajuda das redes sociais ou através da elaboração de folders informativos. Isso nos deixa claro que a promoção da Educação Ambiental pode ser difundida de inúmeras formas, promovendo o conhecimento, a cidadania, a preservação ambiental, formando cidadãos mais conscientes e motivados para gerarem ações mais sustentáveis.

Dentre os resultados que mais chamaram a atenção dos jovens foram a quantidade de resíduos orgânicos produzidos em suas residências, que ficou na média de $6,00 \mathrm{~kg}$ por semana (de cada residência), e também com a possíbilidade de dar um destino mais útil e correto à esses resíduos.

Após a exposição dos relatórios, os jovens colocaram suas opiniões pessoais e percebeu-se que a maioria têm interesse em dar continuidade na coleta dos resíduos orgânicos de suas residências para a utilização como compostagem.

Também se observou que durante o experimento, os funcionários do CRAS, bem como os demais grupos lá atendidos, ficaram interessados no trabalho e demonstraram interesse em colocar em prática a separação dos resíduos orgânicos de suas residência: elaborarem a compostagem.

\section{Referências}

ALVES, W. L. Compostagem e vermicompostagem no tratamento do lixo urbano. Jaboticabal: Funep, 1996, 47p.

ANDREOLI, C. U. Resíduos sólidos do saneamento: processamento, reciclagem e disposição final. Rio de Janeiro: ABES, 282P. 2001.

ASHLEY, P. A. Ética e responsabilidade social nos negócios:

estratégias de negócios focadas na realidade brasileira. 2. ed. São Paulo: Saraiva, 2005.

AZEVEDO, M. A (1997). Compostagem de resíduos sólidos orgânicos e operacionais. Departamento de Engenharia Civil, Ed. Universidade Federal de Viçosa, 44p.

BIDONE, F. R. A. Resíduos sólidos provenientes de coletas especiais: Eliminação e Valorização. Rio de Janeiro: ABES. 240 P. 2001. 
BOEIRA, S. L.; FERREIRA, E.; CAMPOS, L. M. S. Relatório Técnico do Projeto de Pesquisa: caracterização geral das organizações de catadores de materiais recicláveis de Santa Catarina e proposta metodológica de modernização e capacitação gerencial. Edital 06/2003. CNPQ - fevereiro 2006.

BOURDIEU, P. A juventude é apenas uma palavra. In: Questões da sociologia. Rio de Janeiro: Marco Zero, 1980, 113 - 114p.

Disponível em:

BRASIL. Constituição (1988). Constituição da República do Brasil. Brasília, DF.

$<$ http://www.planalto.gov.br/ccivil_03/constituicao/constituicao.htm>. Acessado em: 14 set. 2014.

BRASIL. Estatuto da Criança e do Adolescente. Secretaria Especial dos Direitos Humanos. Disponível em: < http://www.sdh.gov.br/sobre/participacao-social/conselho-nacionaldos-direitos-da-crianca-e-do-adolescente-conanda $>$.

Acessado em: 14 set. 2014.

BRASIL. Ministério do Desenvolvimento Social e Combate à Fome. Anais da V

Conferência Nacional de Assistência Social. Brasília, 2005. Disponível em:

http://www.mds.gov.br/cnas/conferencias-nacionais/v-conferencia-nacional>.

Acessado em: 14 set. 2014.

BRASIL, Ministério do Desenvolvimento Social e Combate a Fome - ProJovem Adolescente - Traçado Metodológico. $1^{\text {a }}$ Edição - Brasília, 2009. Disponível em:

$<\quad$ http://www.social.mg.gov.br/images/documentos/Subsecretaria Assistencia Social/bb\%20virtual/Caderno_02_Tracado_Metodologico.pdf > . Acessado em: 13 set. 2014.

BRASIL. Ministério do Desenvolvimento Social e Combate a Fome - ProJovem Adolescente: Serviço Socioeducativo. Disponível em:

$<$ http://www.desenvolvimentosocial.sp.gov.br/portal.php/federais projovem $>$. Acessado em: 13 set. 2014.

BUDZIAK, C. R.; MAIA, C. M. B. F.; MANGRICH, A. S. Transformações químicas da matéria orgânica durante a compostagem de resíduos da indústria madeireira. Curitiba.399-403 P. 2004.

CALDERONI, S. A viabilidade econômica da eciclagem do lixo. Ciência \& Ambiente. Vol. 18. Santa Maria: UFSM, 1999.

CAMPBELL, S. Manual de Compostagem para hortas e jardins: como aproveitar bem o lixo orgânico doméstico; traduzido por Marcelo Johmel. São Paulo,Nobel, 1999. 144p. América, 2005.

CAMPBELL, S. Deixe Apodrecer! Manual de Compostagem. Publicações Europa-

CAPELLI, L. C. M., SASSARÃO, P.R.G. Produção de ração animal a partir do lixo. Campinas: Projeto Phoenix, 1984.

CARDOSO, P. F. G. "Metodologia". In: "Relatório de monitoramento e avaliação PROASF". São Paulo: CEDECA/IBEAC, 2005, 27 p.

CHENNA, S. I.M. Programa de Educação a distância em gestão integrada de resíduos sólidos: Un. 2: Plano de gerenciamento integrado dos serviços de limpeza urbana. Rio de Janeiro. IBAN, 2001. $65 \mathrm{p}$.

CONGRESSO DE BELGRADO. Carta de Belgrado 1975 - Uma estrutura Global para a Educação Ambiental. Disponível em:

$<$ http://www.mma.gov.br/port/sdi/ea/deds/pdfs/crt belgrado.pdf > . Acesso em: set 2014. 
CURY, B. Os muitos desafios da política nacional da juventude. In: AVRITZER, Leonardo (Org.). Experiências nacionais de participação política. São Paulo: Editora Cortez, 2009.

DEMO, P. Política social, educação e cidadania. Campinas, SP. Papirus, 1994. 31p.

DIAS, G. F. Educação ambiental: princípios e práticas. 9. ed. São Paulo: Gaia, 2004. 92p.

DOCUMENTO: Declaração Final da Conferência das Nações Unidas sobre

Desenvolvimento Sustentável (RIO+20): O futuro que queremos. Rio de Janeiro, 2012. Disponível em: <http://www.rets.org.br/sites/default/files/O-

Futuro-que-queremos1.pdf $>$. Acesso em 14/01/2013.

FERREIRA, M. L. S. Proposta de um sistema alternativo de coleta seletiva de resíduos sólidos domiciliares, executada por catadores (carrinheiros) na cidade de Cianorte - Paraná. 2000. Disponível em:

< http://www.sanepar.com.br/sanepar/sanare/v15/propostapag36.html $>$. Acesso em: 11 out. 2014. Cortez, 1996.

FREIRE, P. A importância do ato de ler: em três artigos que se completam. São Paulo:

FREIRE, P. Pedagogia do oprimido. Rio de Janeiro: Paz e Terra,2005. 7 p.

GADOTTI, M. Pedagogia da Terra e cultura de sustentabilidade. In: Revista Lusófona de Educação, 2005, Edição 06, 18 p.

GÓMEZ, J. A. D.; AGUADO, O. V.; PÉREZ, A. G. (Orgs). Serviço Social e Meio Ambiente. São Paulo: Cortz, 2005.

GRIMBERG, E. Coleta Seletiva e Inclusão de Catadores: Fórum do Lixo e Cidadania da Cidade de São Paulo. Experiências e Desafios. São Paulo. Instituto Pólis.

INÁCIO, C. T.; MILLER, P. R. M. Compostagem: ciência e prática para a gestão de resíduos orgânicos. Rio de Janeiro, Embrapa, 2009. 156 p. JACOBI, P. Educação ambiental, cidadania e sustentabilidade. Caderno de Pesquisa, março 2003, nº. 118, pág. 189-206.

JAHNEL, M. C. Compostagem: a outra metade da reciclagem. São Paulo: IPT:CEMPRE, 1997.

KIEHL, E. J. Fertilizantes orgânicos. Piracicaba, Ceres, 1985. 482 p.

KIEHL, E. J. Manual de compostagem: maturação e qualidade do composto. $4^{\text {a }}$ edição. Piracicaba: Esalg, 2005. 173 p.

KRAMER, M.; GOLVEIA, M. C. S. (Orgs.). Estudos da Infância, educação e práticas sociais. Petrópolis, Rio de Janeiro: Vozes, 2008. Coleção ciências Sociais da educação. 171 - 172 p.

LEI FEDERAL: 9.795, de 27 de abril de 1999. Política Nacional de Educação Ambienal. Disponível em:< http://www.planalto.gov.br/ccivil_03/leis/19795.htm.> Acesso em 14 out 2014.

LEI FEDERAL: 10.836, de 09 de janeiro de 2004. Programa Bolsa Família. Disponível em: < http://www.planalto.gov.br/ccivil_03/_ato2004-2006/2004/lei/110.836.htm. > Acesso em: 09 set. 2014. 
LEI FEDERAL: 12.305, de 02 de agosto de 2010. Política Nacional dos Resíduos Sólidos>. Acesso em: 11 out. 2014.

LIMA, A. M. M. Conceito d. Disponível em: < http://www.planalto.gov.br/ccivil 03/ ato2007-2010/2010/lei/112305.htme Meio Ambiente. Disponível em: http;//ambient edomeio.com/2007/07/29/conceito. Acesso em: 10 out. 2014.

LOPES, A. S. Manual internacional de fertilidade do solo. Piracicaba: Potafos, 1998. $12 \mathrm{p}$.

MARCATTO, C. Educação Ambiental: conceitos e princípios. Belo Horizonte: FEAM, 2002. 14 p.

MATOS, A. T. et al. Compostagem de alguns resíduos orgânicos, utilizando-se águas residuárias da suinocultura como fonte de nitrogênio. Revista brasileira de engenharia agrícola e ambiental. Campina Grande, 199-203 P.1988.

MICHELS, I.; MATTOSINHO, C.; ESTIVAL, K. e Sabadin, C. Resíduos Sólidos Urbanos. Campo Grande - MS: Ed. UFSM, 2004.

NBR 10.404/87: Resíduos solidos: Classificação. Disponível em: < http://www.aslaa.com.br/legislacoes/NBR\%20n\%2010004-2004.pdf.> Acessado em: 15 out. 2014.

NETO, P. J. T., Manual de Compostagem . Belo Horizonte, 1996. UNICEF, 56 p.

NOGUERA, J. O. C. Palestra: Coleta seletiva domiciliar. Curso de Especialização em Educação Ambiental UFSM. Disciplina Abordagem das Questões Ambientais: Poluição Urbana, Ar e Resíduos Sólidos e Urbanos(2010). Disponível em: http://cead.ufsm.br/moodle2_UAB/course/view.php?id=993. Acessado em: 15 nov. 2014.

ORTIZ, L.; SALAMANCA, F.. "Cuidaddanía juvenil y el diseño y evaluación de políticas". Santiago, 2000. Mimeografado.

PEIXOTO, R. T. G. Compostagem: Princípios, prática e perspectivas em sistemas orgânicos de produção. Brasília, Embrapa, 387-422 p. 2005

PÉREZ, A. G.; JOSÉ, A. D.; AGUADO, O. V. (orgs). Serviço social e meio ambiente. São Paulo: Cortez, 2005.

SÊDA, E. ABC do Estatuto da Criança e do Adolescente Comentado. Rio de Janeiro: material impresso. 1991. Disponível em: < http://www.mprs.mp.br/areas/infancia/arquivos/comentart.pdf. $>$ Acesso em: 15 out. 2014.

SILVA, E. Como fazer o lixo virar Compostagem Doméstica. Disponível em: $<$ http://pt.slideshare.net/furabolha/compostagem-domstica-13796150. > Acessado em: 28 jul. 2014.

SORRENTINO, M., TBILISI, A., TESSALONIKI, A. A educação ambiental no Brasil. In: JACOBI, P. et al. Educação, meio ambiente e cidadania: reflexões e experiências. São Paulo: SMA. 1998. p.27-32.

SOUZA, E. R. et al. Construindo Cidadania Ambiental. Belo Horizonte: Projeto Inovar, 2008. 
SOUZA, L.; REZENDE, P. L.; Manual de horticultura orgânica. $2^{\circ}$ ed. Viçosa: Aprenda fácil. 843 p. 2006.

TAMAIO, I. A Mediação do professor na construção do conceito de natureza. Campinas, 2000. Dissertação de Mestrado FE/Unicamp.

TOZONI-REIS, M. F. de C. Temas ambientais como "temas geradores": contribuições para uma metodologia educativa ambiental crítica, transformadora e emancipatória. Educ. rev. [online]. 2006, n.27, pp. 93-110. Disponível em: $<$ http://educa.fcc.org.br/scielo.php?script=sci_abstract\&pid= S0104$40602006000100007 \& 1 n g=e n \&$ nrm=isso. > Acessado em: 5 janeiro de 2015.

TRINDADE, R.L. P. Desvendando as determinações sócio-históricas do instrumental técnico-operativo do Serviço Social na articulação entre demandas sociais e projetos profissionais. Revista Temporalis, Ano II, n. 4, p. 21-42, julho a dezembro/2001.

UNESCO - Organização das Naçãoes Unidas para a Educação a Ciência e a Cultura. Educação para o Desenvolvimento Sustentável no Brasil. Disponível em: $<$ http://www.unesco.org/new/pt/brasilia/natural-sciences/education-for-sustainabledevelopment.> Acessado em: 14 out. de 2014.

ZANETTI, I. C. B. B. Educação Ambiental, Resíduos Sólidos Urbanos e Sustentabilidade: Um estudo de caso sobre o sistema de gestão de Porto Alegre/RS. 2003. Disponível em: < http://pt.scribd.com/doc/67227685/Educacao-Ambiental-residuos-solidos-urbanos-esustentabilidade\#scribd. > Acessado em: 13 out. 2014.

ZAPATA, T.; AMORIM, M; ARNS, P.C. Desenvolvimento Territorial à Distância. Florianópolis: SEaD/UFSC, 2007. In: ZAPATA, T. Desenvolvimento Territorial Endógeno Conceitos, Dimensões e Estratégias. Florianópolis: SEaD/UFSC, 2007. 23-61 p 